\title{
Modern Approaches for Realization of Training Operators of Mining Machines at Mining Enterprises
}

\author{
Velikanov VS* \\ Associate Professor, Nosov Magnitogorsk State Technical University, Russia \\ *Corresponding author: Velikanov Vladimir, Associate Professor, Nosov Magnitogorsk \\ State Technical University, Russia, Email: rizhik_00@mail.ru
}

\section{Mini Review \\ Volume 2 Issue 4}

Received Date: August 02, 2018

Published Date: August 13, 2018

DOI: $10.23880 /$ eoij-16000172

\section{Abstract}

This study investigates the quality issue of the in-house training process for mining machine operators. The authors prove the urgency of the designated problem. The changes in modern society, as well as the development of science and technology have a direct impact on the vocational education system. This paper describes the main aspects of the inhouse training process of mining machine operators; define the essence, structure, contents, and main directions of its revitalization. The following solutions are proposed in order to improve the quality of the in-house training process: to use the original method based on a rating system of the operator knowledge evaluation, active and interactive forms of using modern training technologies. The authors conducted testing techniques in mining enterprises with the aim of confirming the adequacy of the suggested approaches. The results are given in the work. It was proposed that the methods and tools integration has a positive impact on professional training system.

Keywords: Training Process; Mining Machine Operators; Modern Society

\section{Mini Review}

This study investigates the quality issue of the inhouse training process for mining machine operators. The authors prove the urgency of the designated problem. The changes in modern society, as well as the development of science and technology have a direct impact on the vocational education system. This paper describes the main aspects of the in-house training process of mining machine operators; define the essence, structure, contents, and main directions of its revitalization. The traditional teaching method for fueling machine operators is known to be the exercises on real hardware. However, when being trained on real fueling machines, difficulties may arise in the implementation of such important principles of learning as phasing and continuity; there is no objective control and self-control action of a student's correctness. It must be emphasized that highperformance equipment is diverted from the production process and it wears out in the course of training, further power consumption happens.

The following solutions are proposed in order to improve the quality of the in-house training process: to use the original method based on a rating system of the operator knowledge evaluation, active and interactive 


\section{Ergonomics International Journal}

forms of using modern training technologies. The authors conducted testing techniques in mining enterprises with the aim of confirming the adequacy of the suggested approaches. The results are given in the work. It was proposed that the methods and tools integration has a positive impact on professional training system. The authors suggested assessing the quality of training and simulator training of operators on the generalized criteria - the activity efficiency coefficient $\left(\mathrm{k}_{\mathrm{ef}}\right)$. The procedure includes three main components: an analysis of the components that make up the structure of the production activities of operators; evaluation of each group, and the indicators that determine the production efficiency; forming the preliminary report and analyzing the results [1-4].

Furthermore, it has been suggested that the staff inhouse development is the most important factor of the enterprise long-term success. The process of the management system organization in the field of training for mining companies involves the development and implementation of corresponding recruitment policy at each enterprise. Its main areas must become the following ones: to identify the needs of the enterprise in the labor force both in its quantity and in quality; to introduce the definite measures for improvement in professional skills use and increase; to monitor the quality of training; to develop the further in-house training path, taking into account the current labor market and the specifics of the mining industry.

The training center of an enterprise is created in the structure of its staffing services and is a new type of an intra-school. Its main tasks include the organization of skilled workers training with a focus on specifics and the main directions of the production process development, as well as taking into consideration the existing level of the student training. The monitoring results illustrated that promising ones are the operators with experience of 5-10 years, from the point of view of the performance of their production functions, as the received and earned value of theoretical knowledge, backed by achieved skills, allow to realize the potential of machinery and to ensure performance in compliance with specifications.

\section{References}

1. Velikanov VS (2012) Test methods and training facilities in the system of professional skill improvement of mining machinery operators. Mining Journal 9: 131-133.

2. Velikanov VS, Ilina EA, Dyorina NV (2016) Structural and circuit design solution arguments of mine excavators ergonomics management. Procedia Engineering 105: 1215-1220.

3. Velikanov VS (2012) Methodology to evaluate the professional competence of mining - transport machines operators. Mining Journal 2: 114-117.

4. Velikanov VS, Shabanov AA (2012) Evaluation of professional competence of mining and transport machines operators in fuzzy information. Prospects of mining equipment: Proc. Fascicule Mining informational and analytical bulletin, Mountain Book, Moscow, pp: 117-124. 